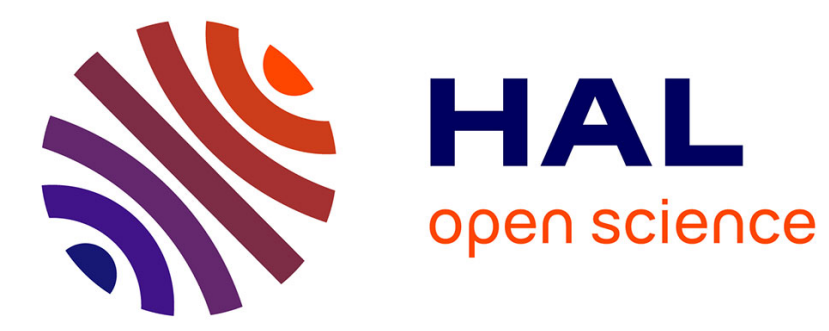

\title{
Electric Vehicles Driven by 5-phase Open-End Winding Machines Fed by Battery and Supercapacitors
}

Duc Tan Vu, Ngac Ky Nguyen, Eric Semail, Walter Lhomme

\section{To cite this version:}

Duc Tan Vu, Ngac Ky Nguyen, Eric Semail, Walter Lhomme. Electric Vehicles Driven by 5-phase Open-End Winding Machines Fed by Battery and Supercapacitors. IEEE VEHICLE POWER AND PROPULSION CONFERENCE VPPC-2019, Oct 2019, Ha Noi, Vietnam. pp.6. hal-02318984

\section{HAL Id: hal-02318984 \\ https://hal.science/hal-02318984}

Submitted on 17 Oct 2019

HAL is a multi-disciplinary open access archive for the deposit and dissemination of scientific research documents, whether they are published or not. The documents may come from teaching and research institutions in France or abroad, or from public or private research centers.
L'archive ouverte pluridisciplinaire HAL, est destinée au dépôt et à la diffusion de documents scientifiques de niveau recherche, publiés ou non, émanant des établissements d'enseignement et de recherche français ou étrangers, des laboratoires publics ou privés. 


\section{Electric Vehicles Driven by 5-phase Open-End Winding Machines Fed by Battery and Supercapacitors}

\author{
Duc Tan Vu \\ ductan.vu@ensam.eu
}

\author{
Ngac Ky Nguyen \\ ngacky.nguyen@ensam.eu
}

\author{
Eric Semail \\ eric.semail@ensam.eu
}

\author{
Walter Lhomme \\ walter.lhomme@univ-lille.fr
}

Univ. Lille, Arts et Metiers ParisTech, Centrale Lille, HEI, EA 2697 -

L2EP - Laboratoire d'Electrotechnique et d'Electronique de Puissance, F-59000 Lille, France

\begin{abstract}
This paper presents the modeling and control of an Electric Vehicle (EV) driven by a 5-phase Permanent Magnet Synchronous Machine (PMSM). The machine in an open-end winding configuration is supplied by two isolated 5-leg Voltage Source Inverters (VSIs). The inverters are fed by a Hybrid Energy Storage System (HESS) consisting of a battery and Supercapacitors (SCs). To increase the battery lifetime, the SCs are used to provide the high-power requirement during driving operations. In addition, an Energy Management Strategy (EMS) is proposed to take advantages of this $\mathrm{EV}$ architecture. Numerical results are derived to verify workability of the $\mathrm{EV}$ system.
\end{abstract}

Keywords - PMSM, multiphase machine, energy management strategy, open-end winding, supercapacitors, electric vehicle

\section{INTRODUCTION}

Machines with a high number of phases, i.e. greater than three, have been used in several applications such as ship propulsion, aircraft and traction in recent decades due to their advantages such as low torque pulsation, fault tolerance, and reduced per phase power rating [1]. The recent design, modeling, and control of multiphase machines are analyzed in [2]. Threephase open-end winding configurations fed by an inverter and a DC voltage source in the flux-weakening region [3] and in degraded modes [4] have been introduced. The open-end winding topologies supplied by dual inverters and two isolated DC voltage sources with 3-phase machines $[5,6]$ and with multiphase machines $[7,8]$ for automotive applications have been extensively investigated to verify advantages of the architecture. Indeed, with given values of DC bus and power, the machine voltages are doubled, and the currents are divided by two. Moreover, in the case of failure of one inverter, the remaining healthy inverter can operate independently, which helps to resume quickly the operation of the drive system. In an EV system, the open-winding structure allows also to use two different DC sources to split the peak power demands that occur in accelerations and decelerations.

The degradation of battery in EVs has been one of the most challenging problems. In driving operations, the battery lifetime is badly affected by peak values of the power demands [9, 10]. Besides other factors affecting the battery aging process, the RMS value of battery current is considered as one of critical criteria having impacts on the battery lifetime [11]. In this context, the combination between batteries with the high energy density and supercapacitors with the high power density is one of promising solutions, tackling the problem of high battery RMS currents $[12,13]$. Supercapacitors can be used in accelerations and decelerations (short-term power demand) while the battery is used for operations at constant speeds. The EVs driven by wye-connected winding 3-phase machines fed by single inverter, using batteries and supercapacitors, have been investigated in [14-17].

In this paper, the proposed EV system is comprised of a 5phase open-end winding machine fed by two independent inverters with HESS. The drive system is described by the Energetic Macroscopic Representation formalism (EMR) [18]. Due to the characteristics of the multiphase machine, a proposed EMS enables to control four power flows within the drive system. In addition, thanks to the supercapacitors, the battery current is smoothly regulated, hence, the battery lifetime can be increased. The workability of the architecture is verified by simulation results.

The paper is organized as follows: section II describes the modeling and control of the EV; in section III, an EMS is proposed to distribute the power flows of the EV; the simulation results are presented in section IV.

\section{Modeling And Control Of The Electric Vehicle}

The EV architecture in this study is shown in Fig. 1, consisting of a 5-phase PM machine fed by 2 VSIs. The first inverter, namely VSI 1, is supplied by a Li-ion battery package and the second inverter, namely VSI 2 , is connected to SCs. The machine drives a wheel and chassis through a gearbox. In this section, all elements of the studied system will be represented by the EMR formalism. EMR is a functional description of energetic systems for control purpose. The system is split into elementary subsystems in interaction [18]. All subsystems of the studied EV are interconnected as in Fig. 2. The models of subsystems are described in this section. Inversion-based control laws (IBC) [18] are applied to define controllers (in light blue parallelograms) of the EV. In addition, an EMS, controlling the power flows within the drive system as well as to help extend the battery lifetime, is analyzed in section III.

\section{A. Sources and inverters}

Energetic models used for the battery and SCs are described in (1-3). 


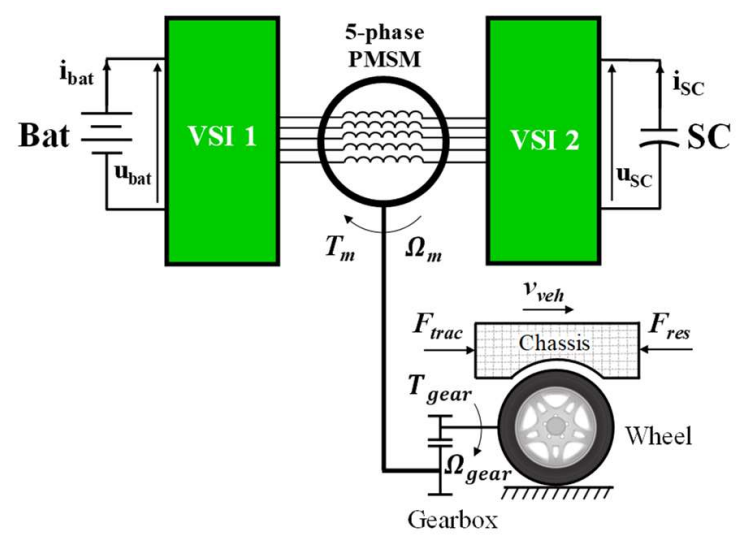

Fig. 1. Configuration of the studied system

$$
\begin{aligned}
& u_{b a t}=u_{O C V}(S o C)-r_{b a t} \cdot i_{b a t} \\
& S o C=100 \% \cdot\left(1-\frac{1}{3600 C_{b a t}} \int i_{b a t} d t\right) \\
& u_{S C}=u_{S C 0}-\frac{1}{C_{S C}} \int i_{S C} d t-r_{S C} \cdot i_{S C}
\end{aligned}
$$

where $u_{b a t}$ is the battery voltage; $u_{O C V}(S o C)$ is the battery open-circuit voltage (OCV) depending on the state of charge of the battery package (SoC); $r_{b a t}$ is the battery equivalent series resistance; $i_{b a t}$ and $C_{b a t}$ are the battery current and capacity respectively; $u_{S C}$ and $u_{S C 0}$ are the SCs instantaneous voltage and the initial SCs voltage; $r_{S C}$ is the SCs series resistance; $i_{S C}$ and $C_{S C}$ are the SCs current and SCs capacitance respectively.

The average linear models of two 5-leg inverters VSI 1 and VSI 2 are shown in (4-5).

$$
\left\{\begin{array}{l}
\underline{u}_{i n v 1}=\underline{m}_{1} \cdot u_{b a t} \\
i_{\text {bat }}=\underline{m}_{1}^{T} \cdot \underline{i}_{i n v 1}
\end{array} ;\left\{\begin{array}{l}
\underline{u}_{i n v 2}=\underline{m}_{2} \cdot u_{S C} \\
i_{S C}=\underline{m}_{2}^{T} \cdot \underline{i}_{i n v 2}
\end{array}\right.\right.
$$

where $\underline{u}_{i n v 1}$ and $\underline{u}_{i n v 2}$ are the 5-dimentional output phase voltage vectors of VSIs 1 and 2 respectively; $\underline{i}_{i n v 1}$ and $\underline{i}_{i n v 2}$ are the 5-dimentional current vectors of VSIs 1 and 2 respectively; $\underline{m}_{1}$ and $\underline{m}_{2}$ are the duty cycles of VSIs 1 and 2 respectively.

Owing to the open-end winding structure, the phase voltages of the 5-phase machine are determined as in (6).

$$
\begin{aligned}
\underline{u}_{m}=\left(\underline{u}_{i n v 1}-\underline{u}_{i n v 2}\right)[M A] \\
\text { with }[M A]=\left[\begin{array}{rrrrr}
4 / 5 & -1 / 5 & -1 / 5 & -1 / 5 & -1 / 5 \\
-1 / 5 & 4 / 5 & -1 / 5 & -1 / 5 & -1 / 5 \\
-1 / 5 & -1 / 5 & 4 / 5 & -1 / 5 & -1 / 5 \\
-1 / 5 & -1 / 5 & -1 / 5 & 4 / 5 & -1 / 5 \\
-1 / 5 & -1 / 5 & -1 / 5 & -1 / 5 & 4 / 5
\end{array}\right]
\end{aligned}
$$

where $\underline{u}_{m}$ is the 5-dimentional phase voltage vector of the 5phase machine.

The EMRs of the sources and inverters are described in Fig. 2. The battery and SCs are represented as source elements (green ovals). The inverters are described by conversion elements (orange squares) and the voltages and currents are merged by a coupling element (interleaved orange squares). The pictograms of different elements are described in Fig. 2.

\section{B. 5-phase PM machine}

To model the 5-phase PM machine, the following assumptions are considered: 5-phase windings are equally shifted and open-ended; the saturation of the magnetic circuits is not considered in the calculation of the back-EMFs and fluxes; and no reluctance effect.

Clarke and Park transformation matrices are applied to convert the machine parameters from natural frame to rotating frames as expressed in (7). According to [19], in rotating frames, the real 5-phase machine is equivalent to three fictitious machines (the first 2-phase machine, the second 2-phase machine and the zero-sequence machine). Each fictitious machine consists of a given group of harmonic components. Ideally, if each fictitious machine has only one harmonic, values of currents and back-EMFs in d-q frames are constant, facilitating the use of simple controllers such as proportional-integral (PI). Therefore, it is assumed that the first machine only has the first harmonic back-EMF while the second machine only consists of the third harmonic one. Other harmonics of back-EMF do not exist in the considered machine. Thus, the first and second machines contribute to the torque generation while the zero-sequence machine does not because its harmonics of back-EMF are equal to zero.

$$
\left[\begin{array}{c}
\underline{u}_{1} \\
\underline{u}_{2} \\
0
\end{array}\right]=\left[T_{\text {Park }}\right]\left[T_{\text {Clarke }}\right] \underline{u}_{m}
$$

where $\underline{u}_{1}=\left[\begin{array}{ll}u_{d 1} & u_{q 1}\end{array}\right]^{T}$ and $\underline{u}_{2}=\left[\begin{array}{lll}u_{d 2} & u_{q 2}\end{array}\right]^{T}$ are voltage vectors of the first and the second machines in rotating d-q frames; $\left[T_{\text {Clarke }}\right]$ and $\left[T_{\text {Park }}\right]$ are Clarke and Park transformation matrices for 5-phase machines [19].

The relationships between voltages, currents and backEMFs of the two fictitious machines are describes as follows:

$$
\left\{\begin{array}{l}
\underline{i}_{1}=\left(\underline{u}_{1}-\underline{e}_{1}\right) \frac{1}{L_{1} s+R_{1}} \\
\underline{i}_{2}=\left(\underline{u}_{2}-\underline{e}_{2}\right) \frac{1}{L_{2} s+R_{2}}
\end{array}\right.
$$

where $\underline{i}_{1}=\left[i_{d 1} i_{q 1}\right]^{T}$ and $\underline{i}_{2}=\left[i_{d 2} i_{q 2}\right]^{T}$ are current vectors of the first and the second machines in rotating $\mathrm{d}$-q frames respectively; $\underline{e}_{1}=\left[\begin{array}{ll}e_{d 1} & e_{q 1}\end{array}\right]^{T}$ and $\underline{e}_{2}=\left[e_{d 2} e_{q 2}\right]^{T}$ are back-EMF vectors of the first and the second machines respectively; $\left(L_{1}, R_{1}\right)$ and $\left(L_{2}, R_{2}\right)$ are the inductances and resistances of the first and second machines in rotating frames respectively; $s$ is the Laplace operator.

The total torque of the machine is the sum of torques of the fictitious machines as follows:

$$
T_{m}=T_{1}+T_{2} \text { with }\left\{\begin{array}{l}
T_{1}=\frac{\left[\underline{e}_{1}\right]^{T} \underline{\underline{i}}_{1}}{\Omega_{m}} \\
T_{2}=\frac{\left[\underline{\left.e_{2}\right]^{T} \underline{i}_{2}}\right.}{\Omega_{m}}
\end{array}\right.
$$

where $T_{1}$ and $T_{2}$ are the torques produced by the first and second machines; $T_{m}$ and $\Omega_{m}$ are the total torque and rotating speed of the machine rotor. 


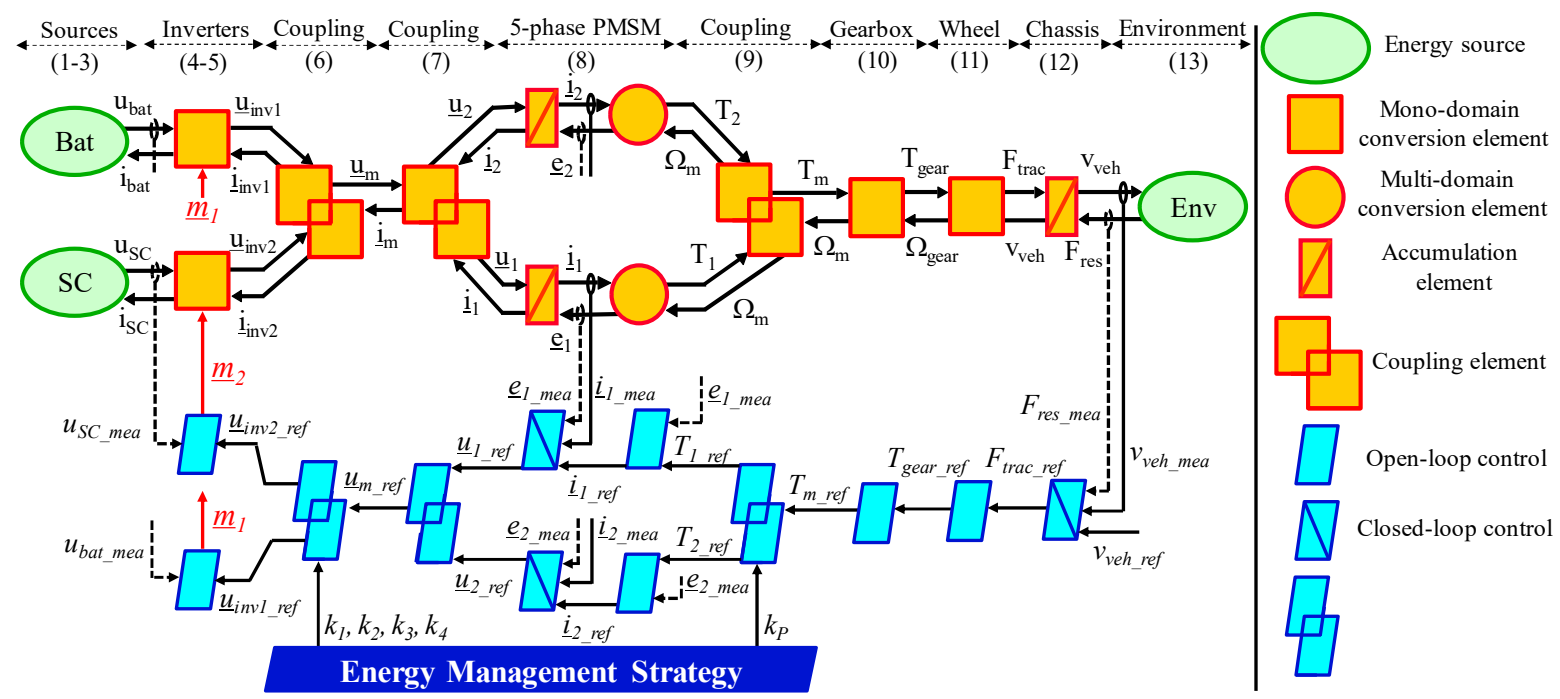

Fig. 2. Energetic macroscopic representation and inversion-based control of the studied electric vehicle

The model of the 5-phase PM machine is represented by EMR as shown in Fig. 2. A coupling element represents the conversion from natural frame to rotating frames. The machine windings are described as accumulation elements with orange crossed rectangles. The electro-mechanic conversions from electrical variables (currents and back-EMFs) to mechanical variables (torque and rotating speed) are depicted by multi-domain elements (orange circles). Finally, the torques by fictitious machines $\left(T_{1}, T_{2}\right)$ are merged by a coupling element to obtain the real machine torque $T_{m}$.

\section{Gearbox and wheel}

The gearbox is considered as ideal (no losses). It is used to reduce the machine speed and increase the torque. The wheel is assumed to be a cylinder and its linear velocity is the same as the velocity of the EV (bicycle energetic model). Their mathematic models are described in (10-11) and represented by EMR as in Fig. 2.

$$
\left\{\begin{array}{c}
T_{\text {gear }}=T_{m} \cdot K_{\text {gear }} \\
\Omega_{m}=\Omega_{\text {gear }} \cdot K_{\text {gear }}
\end{array} ; \quad\left\{\begin{array}{l}
F_{\text {trac }}=T_{\text {gear }} \cdot \frac{1}{R_{\text {wheel }}} \\
\Omega_{\text {gear }}=V_{\text {veh }} \cdot \frac{1}{R_{\text {wheel }}}
\end{array}\right.\right.
$$

where $T_{\text {gear }}$ and $K_{\text {gear }}$ are the gearbox torque and gearbox ratio respectively; $\Omega_{\text {gear }}$ is the reduced rotating speed of the drive system after the gearbox; $F_{\text {trac }}$ is the traction force that drive the EV; $R_{\text {wheel }}$ is the radius of the wheel; $V_{v e h}$ is the linear velocity of the wheel as well as of the EV.

\section{Chassis and environment}

The chassis and environment models are described in (1213) and depicted by EMR as in Fig. 2.

$$
\begin{aligned}
& v_{\text {veh }}=\frac{F_{\text {trac }}-F_{\text {res }}}{m_{\text {veh }} \cdot s} \\
& F_{\text {res }}=F_{\text {aero }}+F_{\text {roll }}+m_{\text {veh }} \cdot g \cdot \sin \alpha \\
& \text { with }\left\{\begin{array}{c}
F_{\text {aero }}=0,5 \cdot \rho C_{w} A\left(v_{\text {veh }}+v_{\text {wind }}\right)^{2} \\
F_{\text {roll }}=f_{\text {roll }} \cdot m_{\text {veh }} \cdot g \cdot \cos \alpha
\end{array}\right.
\end{aligned}
$$

where $F_{r e s}$ is the total resistant force including the aerodynamic force $F_{\text {aero }}$ and rolling resistant force $F_{\text {roll }} ; m_{v e h}$ is the mass of the vehicle; $\rho$ is the density of the air; $c_{w}$ is the air drag coefficient; $A$ is the front area of the vehicle; $v_{\text {wind }}$ is the wind velocity; $f_{\text {roll }}$ is the rolling resistance coefficient; $g$ is the acceleration due to gravity; $\alpha$ is the slope rate.

\section{E. Inversion-based control of the drive system}

In order to control the vehicle, an inversion-based control scheme is applied as in Fig. 2. The control scheme comprises of local and global levels. Pictograms of the local level are light blue parallelograms while the global level refers to EMS in the blue parallelogram. The local level enables the vehicle to track the velocity profile while the global level is to manage and distribute the energy of the system.

In local control, the accumulation elements are inverted with the crossed light blue parallelograms which correspond to closed-loop controls. Controllers such as proportional-integral, integral-proportional and proportional can be applied. The conversion elements are inverted with the light blue parallelograms corresponding to an open-loop control. The energetic coupling is inverted with the overlapped light blue parallelograms.

\section{ENERGY MANAGEMENT STRATEGY}

\section{A. Power flows in the EV system}

When an EV operates, there is a power demand $\left(P_{r e f}\right)$ for the drive system according to the velocity profile. Fig. 3 describes the possible power flows between four sources consisting of the battery package $\left(P_{b a t}\right)$, the supercapacitors $\left(P_{S C}\right)$, the first fictitious machine $\left(P_{l}\right)$ and the second fictitious machine $\left(P_{2}\right)$. The relationships between these powers can be described as follows:

$$
\left\{\begin{array}{c}
P_{r e}=P_{1}+P_{2} \\
P_{\text {ref }}=P_{\text {bat }}+P_{S C}
\end{array} ;\left\{\begin{array}{l}
P_{1}=P_{1 b a t}+P_{1 S C} \\
P_{2}=P_{2 b a t}+P_{2 S C}
\end{array} ;\left\{\begin{array}{c}
P_{b a t}=P_{1 b a t}+P_{2 b a t} \\
P_{S C}=P_{1 S C}+P_{2 S C}
\end{array}\right.\right.\right.
$$

where $P_{1 b a t}$ and $P_{2 b a t}$ are power flows between the battery and the first and second machines respectively; $P_{1 s c}$ and $P_{2 s c}$ are 


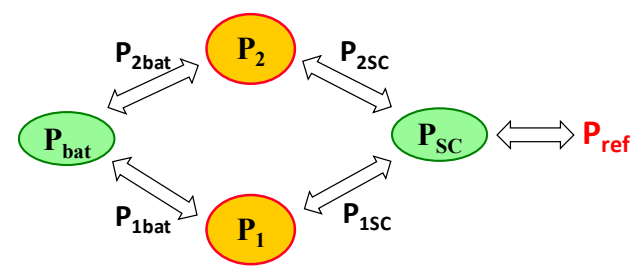

Fig. 3. Possible power flows of the studied electric vehicle

power flows between the SCs and the first and second machines respectively.

\section{B. Proposed Energy Management Strategy}

The proposed EMS allows to manage the powers between the first and the second fictitious machines using the power ratio $k_{P}$ as shown in (17). In addition, in each fictitious machine, to control the powers of the battery and supercapacitors, lowpass filters are applied as shown in Fig. 4. The filter time constants $\tau_{L P F}$ and $\tau_{L P F 2}$, in other words, the cut-off frequencies, can be determined as in [20], depending on response times and sizing of equipment, even the driving cycle. By using the filters, the power flows between the two fictitious machines, battery and SCs can be expressed in (18-19).

$$
\begin{aligned}
& k_{P}=\frac{T_{1}}{T_{m}}=\frac{T_{1}}{T_{1}+T_{2}}=\frac{P_{1}}{P_{1}+P_{2}}=\frac{P_{1}}{P_{r e f}} \\
& \left\{\begin{array}{l}
P_{1 b a t}=\frac{1}{\tau_{L P F 1} S+1} P_{1} \\
P_{2 b a t}=\frac{1}{\tau_{L P F 2} S+1} P_{2}
\end{array} ;\left\{\begin{array}{l}
P_{1 S}=P_{1}\left(1-\frac{1}{\tau_{L P F 1} S+1}\right) \\
P_{2 S C}=P_{2}\left(1-\frac{1}{\tau_{L P F 2} S+1}\right)
\end{array}\right.\right.
\end{aligned}
$$

\section{Voltage references}

When the power partition within the EV system are determined, the voltage references for inverters VSI 1 and VSI 2 can be calculated by using the method of unity power factor for supercapacitors as presented in [5]. The method allows to charge and discharge the SCs in which the power factor of the second inverter VSI 2, connected to the SCs, equals to 1. Fig. 5a describes an equivalent circuit of the first fictitious machine in $\mathrm{d}-$ $\mathrm{q}$ frame. The equivalent circuit for the second machine can be expressed similarly. The machine voltage reference vectors in d-q frames $\left(\underline{u}_{1}, \underline{u}_{2}\right)$ of the first and second fictitious machines are determined by voltage vectors $\left(\underline{u}_{1 b a t}, \underline{u}_{2 b a t}\right)$ of the first inverter VSI 1 and voltage vectors $\left(\underline{u}_{1 S C}, \underline{u}_{2 S}\right)$ of the second inverter VSI 2 as described in (20). Fig. 5b describes the relationship between battery and SCs voltages in rotating frame of the first fictitious machine. The relationship between the battery and SCs in the second machine is like the first machine.

$$
\left\{\begin{array}{l}
\underline{u}_{1}=\underline{u}_{1 b a t}-\underline{u}_{1 S C}=\underline{u}_{2 b a}-\underline{u}_{2 S C} \\
\underline{u}_{2}
\end{array}\right.
$$

where $\underline{u}_{1 b a t}=\left[\begin{array}{lll}u_{d 1 b a t} & u_{q 1 b a t}\end{array}\right]^{T}$ and $\underline{u}_{1 S C}=\left[\begin{array}{ll}u_{d 1 S C} & u_{q 1 S C}\end{array}\right]^{T}$ are d-q voltage vectors of the battery and SCs respectively, corresponding to the first machine; $\underline{u}_{2 b a t}=\left[u_{d 2 b a t} u_{q 2 b a t}\right]^{T}$ and $\underline{u}_{2 S C}=\left[\begin{array}{ll}u_{d 2 S C} & u_{q 2 S C}\end{array}\right]^{T}$ are d-q voltage vectors of the battery and SCs respectively, corresponding to the second machine.

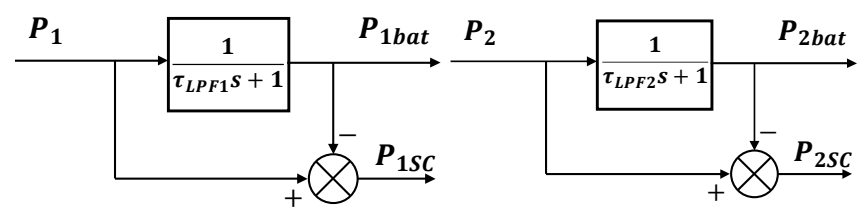

(a)

(b)

Fig. 4. Power distribution between the battery and supercapacitors for: (a) the first machine, $(\mathrm{b})$ the second machine $\left(\tau_{L P F 1}=\tau_{L P F 2}=8 \mathrm{~s}\right)$

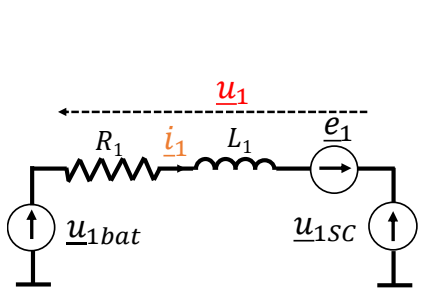

(a)

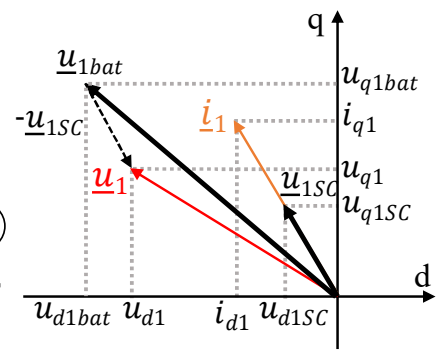

(b)
Fig. 5. Determine voltage references in the first machine: (a) Equivalent circuit, (b) Voltage distribution in rotating frame using unity power factor

In the first machine, there are $4 \mathrm{~d}-\mathrm{q}$ voltages $\left(u_{d 1 b a t}, u_{q 1 b a t}, u_{d 1 S C}, u_{q 1 S C}\right)$ that need to be defined (21-22). Four d-q voltages $\left(u_{d 2 b a t}, u_{q 2 b a t}, u_{d 2 S C}, u_{q 2 S C}\right)$ for the second machine can be similarly calculated as expressed in (23-24). Thus, eight $d-q$ voltage references for the entire system are determined. To define the inverter voltage references in the local level of control of the EMR, four ratios $k_{1}, k_{2}, k_{3}$ and $k_{4}$ between $\mathrm{d}$-q voltage references of VSIs over the d-q total voltage references of the two fictitious machines $\left(u_{d 1}, u_{q 1}, u_{d 2}, u_{q 2}\right)$ are used and described in (25-26) and Fig. 2.

$$
\begin{gathered}
\left\{\begin{array}{l}
u_{d 1 b a t}=u_{d 1}-\frac{i_{d 1}}{\left(i_{d 1}^{2}+i_{q 1}^{2}\right)} P_{1 S C} \\
u_{q 1 b a t}=u_{q 1}-\frac{i_{q 1}}{\left(i_{d 1}^{2}+i_{q 1}^{2}\right)} P_{1 S C}
\end{array} ;\left\{\begin{array}{l}
u_{d 1 S C}=-\frac{i_{d 1}}{\left(i_{d 1}^{2}+i_{q 1}^{2}\right)} P_{1 S C} \\
u_{q 1 S C}=-\frac{i_{q 1}}{\left(i_{d 1}^{2}+i_{q 1}^{2}\right)} P_{1 S C}
\end{array}\right.\right. \\
\left\{\begin{array}{l}
u_{d 2 b a t}=u_{d 2}-\frac{i_{d 2}}{\left(i_{d 2}^{2}+i_{q 2}^{2}\right)} P_{2 S C} \\
u_{q 2 b a t}=u_{q 2}-\frac{i_{q 2}}{\left(i_{d 2}^{2}+i_{q 2}^{2}\right)} P_{2 S C}
\end{array} ;\left\{\begin{array}{l}
u_{d 2 S C}=-\frac{i_{d 2}}{\left(i_{d 2}^{2}+i_{q 2}^{2}\right)} P_{2 S C} \\
u_{q 2 S C}=-\frac{i_{q 2}}{\left(i_{d 2}^{2}+i_{q 2}^{2}\right)} P_{2 S C}
\end{array}\right.\right. \\
\left\{\begin{array}{l}
k_{1}=\frac{u_{d 1 b a t}}{u_{d 1}}=\frac{u_{d 1 S C}}{u_{d 1}}+1 \\
k_{2}=\frac{u_{q 1 b a t}}{u_{q 1}}=\frac{u_{q 1 S C}}{u_{q 1}}+1
\end{array} ;\left\{\begin{array}{l}
k_{3}=\frac{u_{d 2 b a t}}{u_{d 2}}=\frac{u_{d 2 S C}}{u_{d 2}}+1 \\
k_{4}=\frac{u_{q 2 b a t}}{u_{q 2}}=\frac{u_{q 2 S C}}{u_{q 2}}+1
\end{array}\right.\right.
\end{gathered}
$$

\section{NUMERICAL RESULTS}

The studied EV system is simulated with the parameters as described in Table 1. In this table, parameters of the vehicle, battery, SCs and the electrical machine are given. The 5-phase machine to validate the workability of the drive system in this study is chosen so that the second fictitious machine consists of the third harmonic with its amplitude similar to the first harmonic of the first machine. Therefore, the two machines can share alike powers, leading to more possibilities in power management. In this simulation, the power is equally distributed in- 
Table 1. Parameters Of The Vehicle

\begin{tabular}{|c|c|c|c|}
\hline Parameter & Nomenclature & Unit & Value \\
\hline \multicolumn{4}{|l|}{ Vehicle } \\
\hline Curb weight & $m_{v e h}$ & $\mathrm{~kg}$ & 692 \\
\hline Rolling resistance coefficient & $f_{\text {roll }}$ & p.u & 0.02 \\
\hline Aerodynamic standard & $c_{w} A$ & $m^{2}$ & 0.7 \\
\hline Gearbox ratio & $K_{\text {gear }}$ & & 9.32 \\
\hline \multicolumn{4}{|l|}{ Battery } \\
\hline Capacity & $C_{b a t}$ & $A h$ & 102.5 \\
\hline Battery resistance & $r_{b a t}$ & $\Omega$ & 0.0015 \\
\hline Battery OCV & $u_{O C V}$ & $V$ & 300 \\
\hline Mass & & $\mathrm{kg}$ & 330 \\
\hline \multicolumn{4}{|l|}{ Supercapacitors } \\
\hline SCs capacitance & $C_{S C}$ & $F$ & 30 \\
\hline SCs resistance & $r_{S C}$ & $\Omega$ & 0.04 \\
\hline SCs nominal voltage & $u_{\text {SCnom }}$ & $V$ & 90 \\
\hline Mass & & $\mathrm{kg}$ & 18.9 \\
\hline \multicolumn{4}{|l|}{ 5-phase PM machine } \\
\hline Maximal Power & $P_{\max }$ & $k W$ & 15 \\
\hline Number of phases & & & 5 \\
\hline Number of pole pairs & $p_{p}$ & & 8 \\
\hline Stator resistance & $R_{1}=R_{2}$ & $\Omega$ & 0.0324 \\
\hline Inductance & $L_{1}$ & $m H$ & 0.102 \\
\hline Inductance & $L_{2}$ & $m H$ & 0.158 \\
\hline Speed-normalized first harmonic EMF & $E_{l n}$ & $\mathrm{~V} / \mathrm{rad} / \mathrm{s}$ & 0.0874 \\
\hline Speed-normalized third harmonic EMF & $E_{3 n}$ & $\mathrm{~V} / \mathrm{rad} / \mathrm{s}$ & 0.1181 \\
\hline Rated RMS current & $I_{R M S}$ & $A$ & 190 \\
\hline Maximum peak phase current & $I_{\text {peak }}$ & $A$ & 280 \\
\hline
\end{tabular}

-to two fictitious machines $\left(k_{P}=0.5\right)$. The time constants of the low-pass filters $\tau_{L P F 1}$ and $\tau_{L P F 2}$ are set to $8 \mathrm{~s}$ according to the sizing of the battery and supercapacitors. To verify the studied EV, the velocity profile of Worldwide harmonized Light vehicles Test Cycle (WLTC) is applied with the maximum velocity of $64 \mathrm{~km} / \mathrm{h}$. The driving cycle time is 1022 seconds. The proportional controller is used to control speed while the currents are controlled by PI controllers. Fig. 6 shows that the simulated velocity tracks properly the velocity reference.

To verify the changes in battery current with the studied structure, a comparison with the EV using the same machine but in the wye-connected winding configuration fed by single inverter and without SCs needs to be made. In Fig. 7, the battery current with the support of SCs is much smaller with a lower maximum peak value (35A) compared to the case without SCs (50A). At some periods of the operation, the peak values of battery current using SCs are reduced by $50 \%$ compared to the case without SCs as shown in zoomed parts of Fig. 7. Moreover, the RMS value of battery current during the driving cycle decreases from 16A to 12A when SCs are used. Thus, from the aforementioned analyses in the introduction section, the battery lifetime can be improved by reducing the RMS battery current.

From Fig. 7, the battery current waveform is smoother, and its values are rarely negative while the SC current is comprised of negative and positive values with the highest peak value up to $153 \mathrm{~A}$. Fig. 8 shows that the SCs have been fully recharged to its nominal voltage $\left(u_{S C n o m}=90 \mathrm{~V}\right)$ at the end of the considered driving cycle. Therefore, all the regenerative energy is recovered to the SCs, which makes the SCs are ready for next operations of the EV. The SC voltage is kept within their limit region from the minimum value $\left(0.5 u_{S C n o m}\right)$ to the nominal value.

In Fig. 9, because the power ratio between the first and sec-

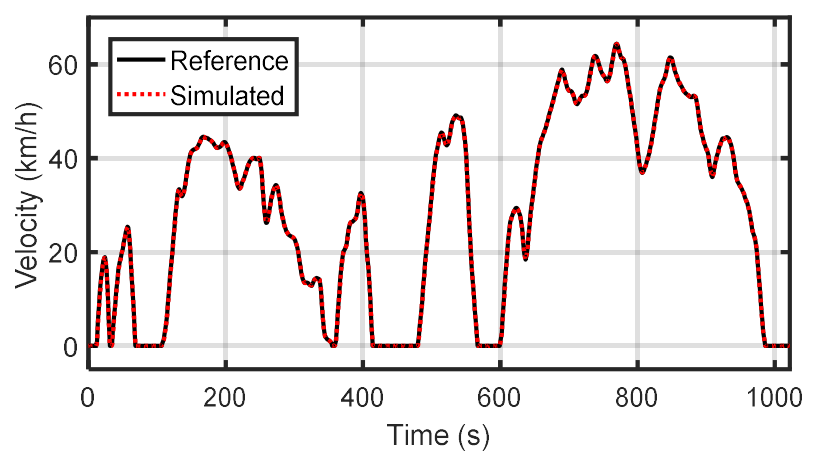

Fig. 6. Velocity of the electric vehicle
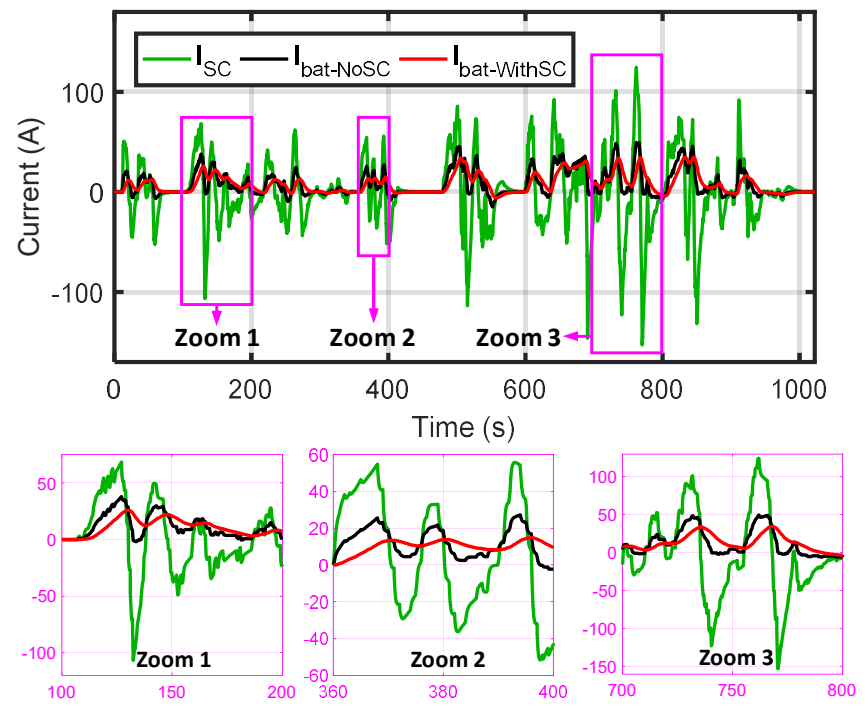

Fig. 7. Currents of the battery and supercapacitors

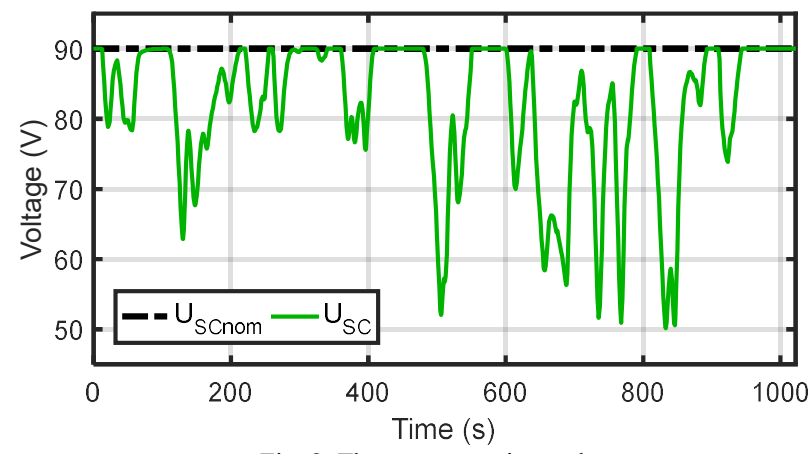

Fig. 8. The supercapacitor voltage

-ond machines $k_{P}$ is set to 0.5 , the total power reference with the maximal value of $14.9 \mathrm{~kW}$ is equally shared by the first and second machines. The power distribution between the battery and SCs in the vehicle is shown in Fig. 10. As the above discussions, the processes of charging and discharging of the SCs are frequent while the battery mostly discharges in the driving cycle. It means that the charging number of the battery is reduced, improving the battery lifetime. In addition, from zoomed parts of Fig. 10, if SCs are not used, the maximum power required for the battery must be equal to the power demand of the entire system with $14.9 \mathrm{~kW}$. The stress on the battery power reduces $30.2 \%$ from $14.9 \mathrm{~kW}$ to $10.4 \mathrm{~kW}$ when SCs are applied, 


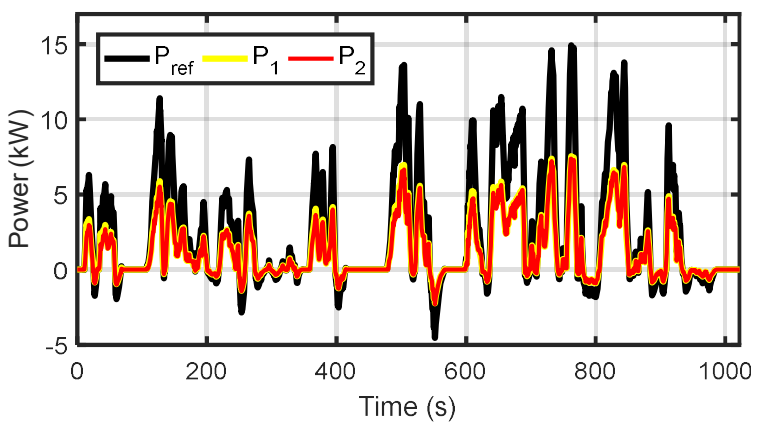

Fig. 9. Power distribution in the first and second machines from a given power reference
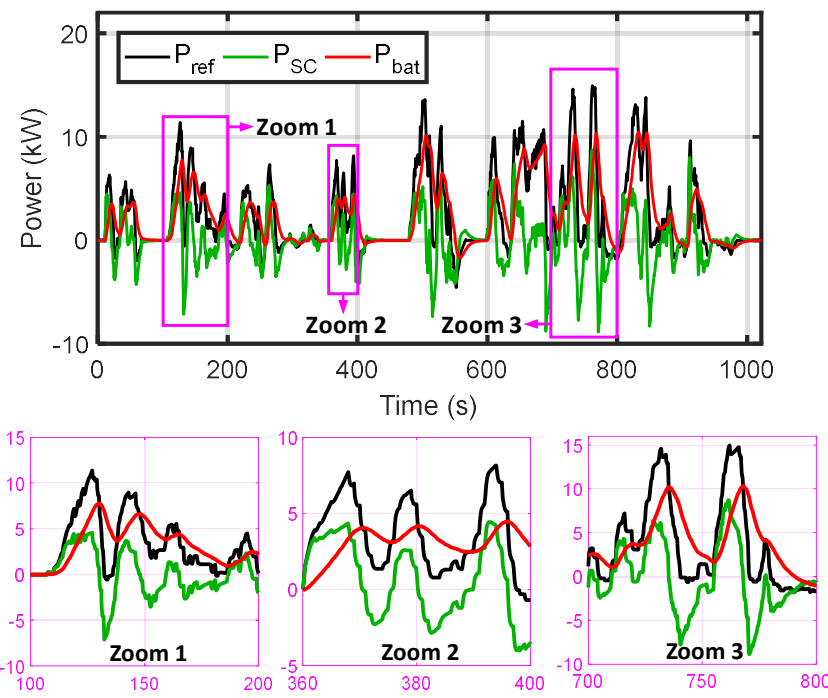

Fig. 10. Power distribution in the battery and supercapacitors from a given power reference

leading to a reduction in the battery dimension. The maximum power of the SCs is $8.9 \mathrm{~kW}$, lower than the power of the battery.

\section{CONCLUSION}

The modeling and control of an electric vehicle driven by a five-phase permanent magnet synchronous machine in openend winding configuration has been detailed in this paper. The two 5-phase inverters have been successfully fed by a hybrid energy storage system consisting of a battery and supercapacitors. With the proposed energy management strategy, the peak and RMS values of battery current are smoothly reduced, improving the battery lifetime. In addition, the energy management strategy enables to control four power flows within the drive system. The simulation results have validated the workability of the proposed strategy in the considered electric vehicle. In future, other advantages (for example, fault-tolerant capability) as well as drawbacks of the system and other energy management strategies need to be investigated.

\section{REFERENCES}

[1] E. Levi, "Multiphase Electric Machines for Variable-Speed Applications," IEEE Transactions on Industrial Electronics, vol. 55, no. 5, pp. $1893-1909,2008$.
[2] F. Barrero and M. J. Duran, "Recent Advances in the Design, Modeling, and Control of Multiphase Machines Part I," IEEE Transactions on Industrial Electronics, vol. 63, no. 1, pp. 449-458, 2016.

[3] P. Sandulescu, F. Meinguet, X. Kestelyn, E. Semail, and A. Bruyère, "Control Strategies for Open-End Winding Drives Operating in the FluxWeakening Region," IEEE Transactions on Power Electronics, vol. 29, no. 9 , pp. 4829-4842, 2014.

[4] O. Béthoux, E. Labouré, G. Remy, and E. Berthelot, "Real-Time Optima Control of a 3-Phase PMSM in 2-Phase Degraded Mode," IEEE Transactions on Vehicular Technology, vol. 66, no. 3, pp. 2044-2052, 2017.

[5] B. A. Welchko, "A double-ended inverter system for the combined propulsion and energy management functions in hybrid vehicles with energy storage," in 31st Annual Conference of IEEE Industrial Electronics Society (IECON), Raleigh, NC, USA, 2005, p. 6 pp.

[6] D. Casadei, G. Grandi, A. Lega, and C. Rossi, "Multilevel Operation and Input Power Balancing for a Dual Two-Level Inverter with Insulated DC Sources," IEEE Transactions on Industry Applications, vol. 44, no. 6, pp. 1815-1824, 2008.

[7] K. K. Mohapatra and K. Gopakumar, "A Novel Split Phase Induction Motor Drive without Harmonic Filters and with Linear Voltage Control for the Full Modulation Range," EPE Journal, vol. 16, no. 4, pp. 20-28, 2006

[8] E. Levi, M. Jones, and W. Satiawan, "A multiphase dual-inverter supplied drive structure for electric and hybrid electric vehicles," in IEEE Vehicle Power and Propulsion Conference, Lille, France, 2010, pp. 1-7.

[9] S. M. Rezvanizaniani, Z. Liu, Y. Chen, and J. Lee, "Review and recent advances in battery health monitoring and prognostics technologies for electric vehicle (EV) safety and mobility," Journal of Power Sources, vol. 256, pp. 110-124, 2014

[10] M. Jafari, A. Gauchia, K. Zhang, and L. Gauchia, "Simulation and Analysis of the Effect of Real-World Driving Styles in an EV Battery Performance and Aging," IEEE Transactions on Transportation Electrification, vol. 1, no. 4, pp. 391-401, 2015.

[11] F. Savoye, P. Venet, M. Millet, and J. Groot, "Impact of Periodic Current Pulses on Li-Ion Battery Performance," IEEE Transactions on Industrial Electronics, vol. 59, no. 9, pp. 3481-3488, 2012.

[12] S. F. Tie and C. W. Tan, "A review of energy sources and energy management system in electric vehicles," Renewable and Sustainable Energy Reviews, vol. 20, pp. 82-102, 2013.

[13] B. Nguyen, R. German, J. P. F. Trovão, and A. Bouscayrol, "Real-Time Energy Management of Battery/Supercapacitor Electric Vehicles Based on an Adaptation of Pontryagin's Minimum Principle," IEEE Transactions on Vehicular Technology, vol. 68, no. 1, pp. 203-212, 2019.

[14] A. Castaings, W. Lhomme, R. Trigui, and A. Bouscayrol, "Comparison of energy management strategies of a battery/supercapacitors system for electric vehicle under real-time constraints," Applied Energy, vol. 163, pp. 190-200, 2016.

[15] P. Golchoubian and N. L. Azad, "Real-Time Nonlinear Model Predictive Control of a Battery-Supercapacitor Hybrid Energy Storage System in Electric Vehicles," IEEE Transactions on Vehicular Technology, vol. 66, no. 11 , pp. 9678-9688, 2017.

[16] O. Gomozov, J. P. F. Trovão, X. Kestelyn, and M. R. Dubois, "Adaptive Energy Management System Based on a Real-Time Model Predictive Control With Nonuniform Sampling Time for Multiple Energy Storage Electric Vehicle," IEEE Transactions on Vehicular Technology, vol. 66 , no. 7, pp. 5520-5530, 2017.

[17] Y. Mahadik and K. Vadirajacharya, "Battery Life Enhancement in a Hybrid Electrical Energy Storage System Using a Multi-Source Inverter," World Electric Vehicle Journal, vol. 10, no. 2, 2019.

[18] A. Bouscayrol, J.-P. Hautier, and B. Lemaire-Semail, "Graphic formalisms for the control of multi-physical energetic systems," in Systemic Design Methodologies for Electrical Energy: Analysis, Synthesis and Management, X. Roboam, Ed. Hoboken, NJ, USA: Wiley, Oct. 2012, pp. $89-124$

[19] E. Semail, X. Kestelyn, and A. Bouscayrol, "Right harmonic spectrum for the back-electromotive force of an n-phase synchronous motor," in the 39th IEEE Industry Applications Conference, Seattle, WA, USA, 2004, vol. 1, pp. 71-78.

[20] T. Christen and M. W. Carlen, "Theory of Ragone plots," Journal of Power Sources, vol. 91, no. 2, pp. 210-216, 2000. 